\title{
Treatment of International Economic Trade in Intergovernmental Panel on Climate Change (IPCC) Reports
}

\author{
Jackie Dawson $^{1}$ (D) Jean Holloway ${ }^{1} \cdot$ Nathan Debortoli $^{1} \cdot$ Elisabeth Gilmore ${ }^{2}$ \\ Accepted: 10 September 2020 / Published online: 1 October 2020 \\ (C) The Author(s) 2020
}

\begin{abstract}
Purpose of the Review Climate change presents significant risks to the international trade and supply chain systems with potentially profound and cascading effects for the global economy. A robust international trade system may also be central to managing future climate risks. Here, we assess the treatment (or lack thereof) of trade in a selection of recent Intergovernmental Panel on Climate Change (IPCC) assessment and special reports using a quantitative text analysis. IPCC reports are considered the preeminent source of relevant climate change information and underpin international climate change negotiations.

Study Findings Results show that international trade has not had substantial coverage in recent IPCC assessments. Relevant keywords associated with trade appear in very limited ways, generally in relation to the words "product" and "transport." These keywords are often referring to emissions associated with transportation and the movement of food and global food systems. The influence of trade is given larger consideration with respect to the costs and trade-offs of climate mitigation policies, especially the interactions with food availability, that appear in Working Group III reports compared with the risks to trade from climate change impacts in Working Group II. Trade in relation to other economic sectors is largely absent as well as risks from potential climate-related trade disruption. There is almost no treatment of the potential impacts, risks, and adaptation strategies to manage the climate related-implications for international trade.

Recommendations Given the importance of trade to economic growth, we recommend that additional attention be paid to trade and related economic issues in future IPCC assessment and special reports, specifically on the interactions of climate impacts and risks on trade and the potential for trade to moderate these risks. To achieve this, there must be efforts to increase the base of scientific literature focused on climate change and international trade as well as increased effort made among IPCC lead authors to review trade literature that may lie outside conventional climate change scholarship.
\end{abstract}

Keywords Climate change $\cdot$ IPCC reports $\cdot$ Trade $\cdot$ Transport $\cdot$ Global economy

This article is part of the Topical Collection on Progress in the Solution Space of Climate Adaptation

Electronic supplementary material The online version of this article (https://doi.org/10.1007/s40641-020-00163-x) contains supplementary material, which is available to authorized users.

Jackie Dawson

jackie.dawson@uottawa.ca

1 Department of Geography, Environment and Geomatics, University of Ottawa, Ottawa, Ontario, Canada

2 Department of International Development, Community and Environment, Clark University, Worcester, MA, USA

\section{Introduction}

International trade is the exchange of goods and services across national borders and currently accounts for approximately $40 \%$ of the entire global economy [1]. Allowing countries to leverage their competitive advantage, by reducing trade barriers and expanding access to global markets, has led to substantial economic growth and poverty alleviation worldwide since 1990 [2, 3]. Over time, the benefits are observed in improved social conditions and reduction in risks to human health, although the gains and losses observed have not all be shared equally or equitably [4]. While international trade has indeed guided considerable economic, social, and health gains, the environmental impact of trade liberalization is more ambiguous. For example, trade-induced growth in the 
economy has resulted in higher emissions of carbon dioxide $\left(\mathrm{CO}_{2}\right)$ - the main pollutant that drives climate change [5]. This itself has been shown to lead to increases in ill health as well as social and economic inequity [6, 7]. Complicating this further is the fact that a substantial portion of the decreases in $\mathrm{CO}_{2}$ emissions observed in developed countries, as a result of globalization and technological modernization enabled by trade, are often offset by increases in international trade flows and the related increases in emissions [8]. It is crucial to develop strategies to promote sustainable global trade patterns while limiting the impacts on future climate change. Some experts have suggested that linkages between different aspects of international trade and climate policy may actually foster a willingness to engage in climate mitigation, with the potential to facilitate co-benefits among related adaptation, and mitigation strategies should they be considered congruently [9-12].

There is a growing literature on the costs associated with climate change mitigation and trade, but the literature on trade and adaptation is much more limited. Computable general equilibrium (CGE) models that are used to evaluate trade patterns and climate mitigation have not generally incorporated climate change impacts [13]. Agriculture has been the most widely investigated climate-related impact in terms of its integration with trade [14]. Specifically, the food price shocks for 2008-2009 prompted a substantial literature on how stresses to agricultural production, indicative of climate change impacts, may be transmitted through trade patterns, including the role of trade distortions in amplifying those shocks $[15,16]$. The effects of trade have also been indirectly included in other economic valuations of climate impacts. For example, the economic costs of sea level rise in Europe have also been evaluated in a CGE framework that allows for the reallocation of resources through trade [17].

More common in the literature, and certainly most prevalent in gray literature, is analysis of the role of extreme events, including storm surge, coastal erosion, hurricanes, and flash floods, in the destruction of key tradeand transportation-related infrastructure that causes major disruptions within international and inter-regional supply chains [18-20]. For example, in the USA, Superstorm Sandy shut down the Port of New York/New Jersey for 8 days resulting in major disruptions to shipping [21]. Washouts of parts of the railroad connecting Churchill to southern Manitoba, Canada, in the summer of 2017, resulted in a complete shutdown of rail transport of goods to Churchill, including the re-supply for remote northern communities [22]. However, many of these studies are found in different disciplinary literatures and tend to focus either on climate impact drivers and their changing severity or on the economic or societal implications of infrastructure damage from extreme events. This lack of integration, or perhaps the absence of systems-based analysis of climate change and trade disruption (observed or projected), challenges but does not limit the possibility of properly assessing the role of climate change in global economic trade.

In addition to creating risks related to trade disruption via infrastructure damage, climate change is also likely to influence a transformation of global trade routes and patterns. For example, reductions in sea ice extent are making Arctic maritime trade routes a new possibility [23-26], and shipping in that region has been increasing rapidly over the past decade $[27,28]$. The opportunity for maritime trade through the Arctic has captured the imagination of global nations for centuries because of the economic benefits related to shorter distances and the relative political stability of the region compared with existing trade corridors in the Southern Ocean. As over $80 \%$ of all goods traded internationally move at some point by ship [29], the transformation in maritime trade routes of the Arctic could create a suite of cascading impacts related to geopolitics, international power dynamics, and environmental and cultural sustainability with major policy relevant implications [30-32].

Given the ever-increasing importance of international trade and the wide range of potential interactions with climate change impacts, risks, and climate policy, it seems timely and appropriate to evaluate the extent to which trade is considered and assessed within Intergovernmental Panel on Climate Change (IPCC) reports. IPCC reports provide a comprehensive assessment of the state of scientific knowledge on climate change and play a critical role in outlining our scientific understanding of observed impacts and future risks associated with a changing climate while offering insight on response options related to mitigation and adaptation [33, 34]. These reports play a fundamental and critical role in shaping the way that climate change is viewed and understood by society and how international climate policies and agreements are negotiated [35-37]. Since 2012, the IPCC has released their Fifth Assessment Report (AR5) as well as special reports focused on (1) lands, (2) oceans and the cryosphere, and (3) the special report on $1.5{ }^{\circ} \mathrm{C}$ warming [26, 38-43], among others [44]. In this paper, we conduct a quantitative text analysis of recent IPCC assessment and special reports to identify trade-related content and the extent to which and how trade has been assessed.

\section{Methods}

The analysis used to identify trade-related content and the extent to which and how trade has been assessed within recent IPCC reports involves several steps (Fig. 1). The first step involved scoping the analysis. Due to time and resource constraints, a selection of assessment and special reports from the 2012-2019 time period was evaluated including the AR5 Synthesis Report: Climate Change 2014 (SYR) 151 pages 


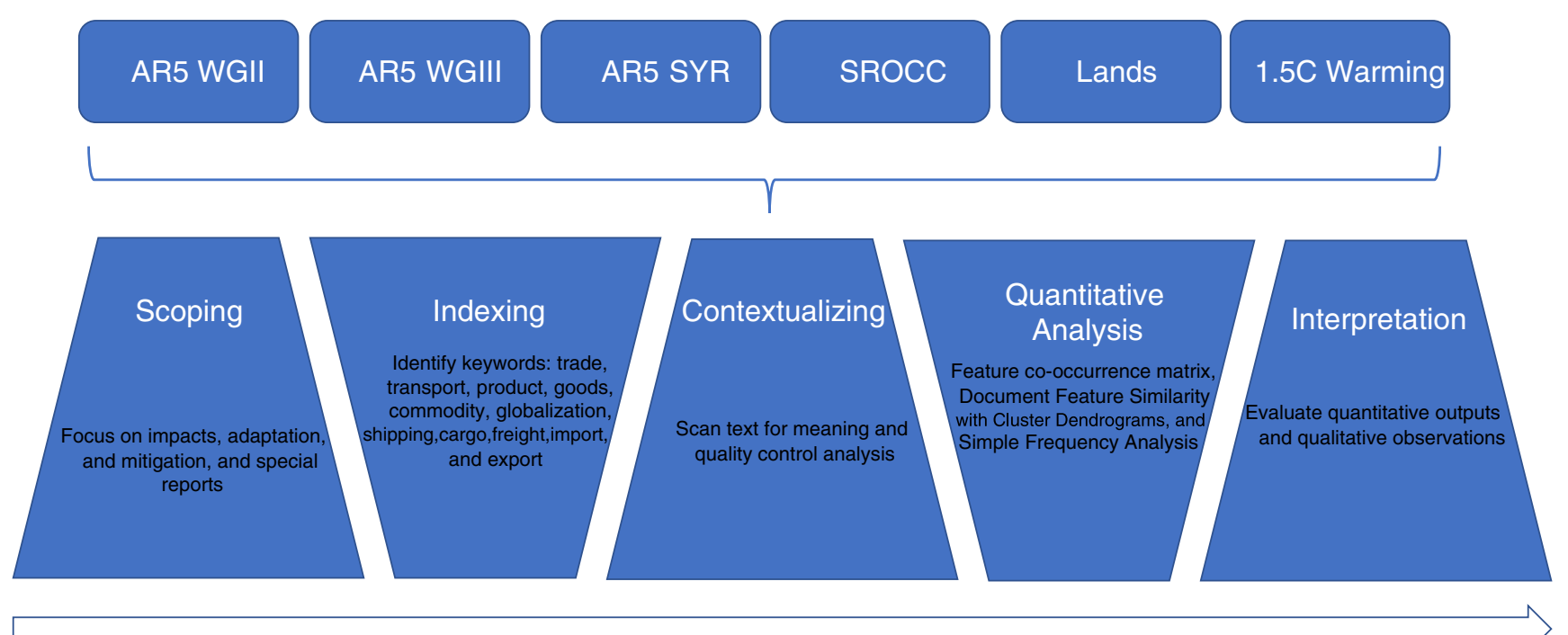

Fig. 1 Study approach

[38]; AR5 WGII: Impacts, Adaptation, and Vulnerability (AR5 WGII) 1820 pages [39, 40]; AR5 WGIII: Mitigation of Climate Change (AR5 WGIII) 1435 pages [41]; the Ocean and Cryosphere in a Changing Climate (SROCC) 755 pages [26]; the Special Report on Climate Change and Lands (SRCCL) 864 pages [42]; and the Special Report on Global Warming of $1.5^{\circ} \mathrm{C}$ (SR15) 616 pages [43] (Scoping-Fig. 1). AR5 WG1 (Physical Basis) and SREX (Special Report on Extreme Events and Disasters) have been excluded from the analysis. An initial scan of the AR5 WGI revealed limited trade related content, and the SREX was released prior to 2012.

A scan of relevant global trade literature is conducted in order to identify trade relevant keywords (Indexing-Fig. 1). The selected keywords identified for the analysis included "cargo," "commodity," "export," "freight," "globalization," "goods," "import," "product," "shipping," "trade," and "transport". Keyword searches, using the identified words, were conducted in each of the six analyzed reports. Once keywords were found, the surrounding paragraph or section of figure or table was extracted, and the extracted text was quality controlled to ensure the meaning and intention reflected the focus of our analysis (Contextualizing-Fig. 1). This was necessary to avoid keywords with multiple meanings, such as "transport" in the SROCC report meaning both the transport of goods and also the transport of water, organisms, and other environmental and physical parameters. In such cases, paragraphs containing keywords that were not contextualized to the focus of this study (i.e., international economic trade) were excluded. We also included possible variations in word terminations (e.g., transport to represent transportation, transporting, etc.). Certain non-relevant content was also excluded from the analysis, notable examples being "trade-offs" and "cap-and-trade." Finally, chapter reference lists were also excluded from the text.
Relevant text from all reports is combined in order to conduct quantitative text analysis, using a tool called Quanteda (Quantitative analysis-Fig. 1) that functions through packages supported by the software platform R [45]. Quanteda is an open-source software that has been used to conduct similar quantitative text analysis [46]. The document containing all text extracted from the IPCC reports was imported into R, where the text was then organized and cleaned using scripts available in Quanteda and adapted for our specific analytical context (see Supplementary Material A). At this point, a series of simplification and quality control steps were taken, including the elimination of unnecessary words, numbers, punctuation, acronyms and symbols, the creation of a text corpus, tokens objects (words), and a document-feature matrix. For this study, we utilized three specific statistical analysis, scaling, and classification tools including simple frequency analysis, feature co-occurrence matrix (FCM), and document feature similarity (cluster dendrograms).

Simple frequency analysis is used to count the number of times keywords are mentioned in each report. During this analysis, word frequencies were not normalized by the length of reports, and therefore, results display the total additive keywords and not the average. FCM is used to record the number of co-occurrences of tokens (i.e., keywords) in each report and to identify the most frequently co-occurring words. This analysis informs similarities in meaning between word pairs and meaning within word patterns. It also reveals latent structures of mental and social representations [47-49]. To improve the visualization of the co-occurrence graph patterns, we adjusted the matrix to consider only words with the highest number of co-occurrences, eliminating any "noise" caused by unnecessary tokens. Cluster dendrograms are used to calculate the similarities among features of interest within documents [50], such as among the preselected keywords used in this 
analysis and their surrounding paragraphs. The height of a keyword in the plot of the cluster dendrogram is proportional to its similarity or dissimilarity to other keywords found in the report. The more dissimilarity the keyword has, the more scattered the term is in the text. The more similarity the keyword has with other keywords, the more interlinked they are. Below we present the results and observations that emerged from the analysis using simple frequency analysis, FCM, and cluster dendrograms (Interpretation-Fig. 1).

\section{Results}

Trade-related keywords occurred very rarely in IPCC reports especially compared with other high frequency words (e.g., "emissions," "energy," "mitigation") (see Supplementary Material B and C). In total, trade-related keywords appear just under 5000 times for all of the IPCC reports analyzed. When isolating just for trade-related keywords, the word that occurred most frequently in all IPCC reports analyzed is "transport" $(n=1692)$. The second highest occurring preselected keyword is "trade" $(n=1269)$, followed by "shipping" $(n=$ $352)$, and then "product" $(n=322)$ (Fig. 2). The keyword with the lowest frequency was "export" $(n=170)$. The IPCC report with the highest number of trade-related keywords was AR5 WGIII $(n=2786)$. In the WGIII report, the word "transport" appears more times than all of the trade-related keywords combined in any of the other reports. Of all of the traderelated keywords, only "product," "transport," and "shipping" appear on any of the ranked lists for all IPCC reports (Table 1).

When further analyzing trade-related keywords in the reports using an FCM approach, it was revealed that certain words tend to dominate the discourse. These words form clusters of information that tend to occur in a similar linguistic context and resemble each other in meaning. This approach allows for a deeper evaluation of the meaning among keywords of interest that extends the simple frequency analysis. It allows one to make inferences about the importance and relation of the keywords in each document and observe some of the general patterns that emerge. For example, the majority of trade-related keywords did not come up as salient or wellconnected words in any of the documents (Table 1; Fig. 3). The only words that occurred with any regularity in an FCM matrix table are "product" and "transport" (Table 1). Within the IPCC reports, the word "product" had the highest co-

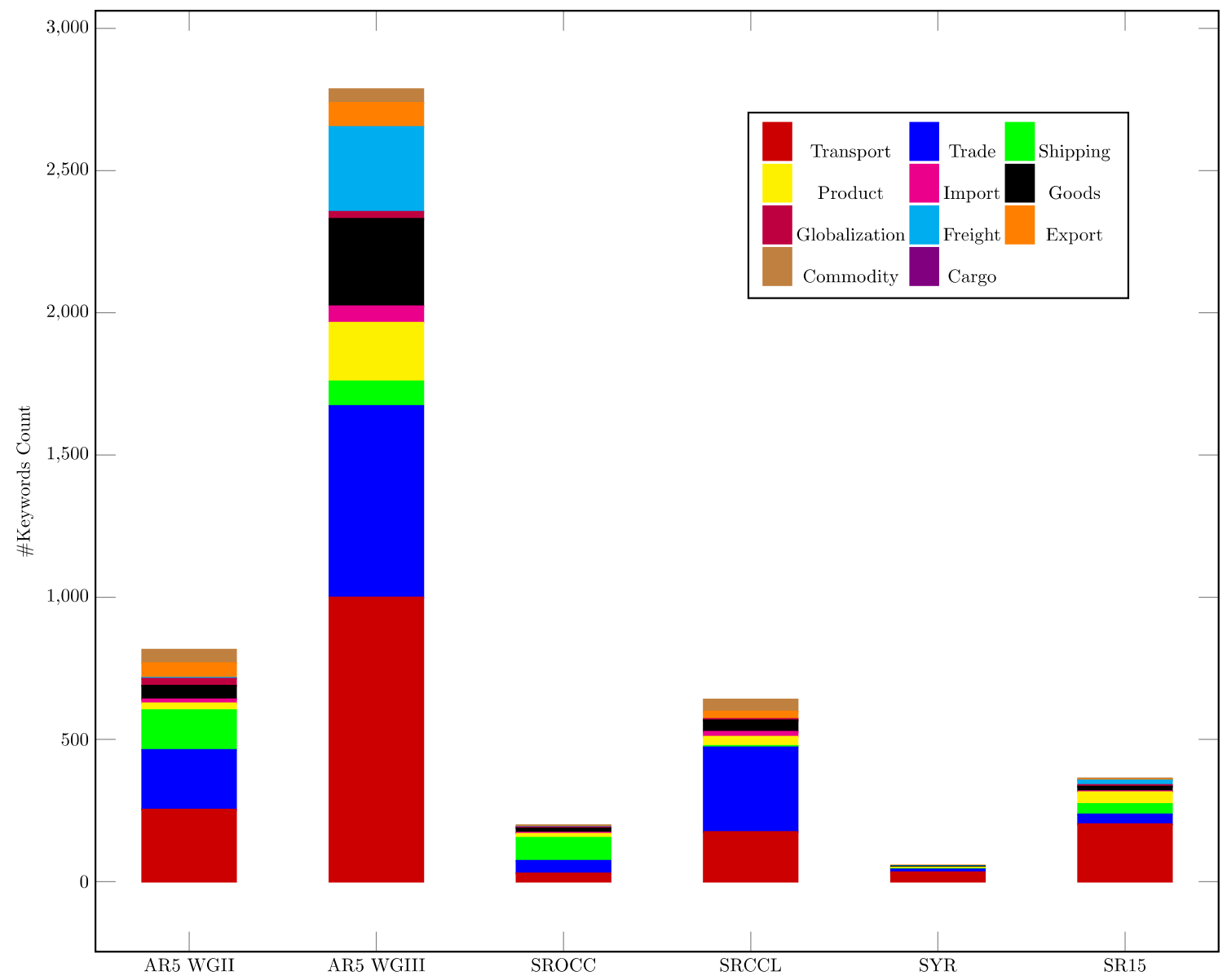

Fig. 2 Simple frequency analysis graph outlining the number of times a keyword is mentioned in each report 
Table 1 Frequency cooccurrence matrix table including the word ranking number of most co-occurrences for each report. Preselected keywords (if ranked) are presented in bold with an asterisk

\begin{tabular}{llllll}
\hline AR5 WGIII & AR5 WGII & SROCC & SRCCL & SR15 & SYR \\
\hline emiss & chang & arctic & food & energi & emiss \\
2703 & 1484 & 120 & 1362 & 275 & 99 \\
*product & climat & chang & *product & *transport & chang \\
1767 & 1459 & 111 & 1097 & 254 & 89 \\
energ & *product & impact & land & *product & sector \\
1568 & 1215 & 103 & 701 & 186 & 73 \\
$*$ transport & increas & increas & emiss & emiss & mitg \\
1126 & 1088 & 98 & 636 & 182 & 71 \\
countri & impact & $*$ ship & chang & sector & climat \\
1092 & 934 & 96 & 627 & 181 & 65 \\
mitig & food & $*$ transport & increas & chang & energi \\
1001 & 883 & 83 & 614 & 160 & 60 \\
use & adapt & sea & climat & pathway & $*$ product \\
970 & 629 & 81 & 599 & 136 & 58 \\
increas & region & risk & system & mitig & high \\
905 & 552 & 81 & 514 & 130 & 56 \\
sector & risk & climat & can & use & impact \\
899 & 532 & 78 & 486 & 117 & 56 \\
develop & high & ocean & agricultur & can & level \\
884 & 529 & 71 & 474 & 111 & 50 \\
\hline & & & & &
\end{tabular}

occurrence among the trade-related keywords, indicating it is a topic that is prevalent in all reports and that the concept is related to many subjects covered in the texts (Fig. 3). However, upon closer contextual analysis, the word "product" usually does not co-occur with any of the other trade related keywords. This indicates that, although the word "product" is linked to many words in the documents, it is likely not occurring in the context of international economic trade. That is, when the word is used in the reports, it is not referring to the movement or trading of "products."

The FCMs also identified areas where subjects are more closely related and emphasized. For example, in the SROCC report, the highest co-occurrence of trade-related keywords focused on the impact and changes occurring as a result of increased shipping and transportation activities in the Arctic (Fig. 2d). However, trade as a general theme did not emerge in the SROCC report beyond this specific example. The FCM analysis also revealed that in the SRCCL report, there are clear word linkages between food production, land use and management of crops, agriculture and forests, and the relations of mitigation and carbon emissions (Fig. 3e), but again limited attention is given to any of the trade-related words or to the concepts associated with global economic trade generally. The SR1.5 report exhibited a larger spectrum of word cooccurrences overall compared with the other reports, likely due to the diverse set of subjects covered by this document, but, again, there was no evidence of trade words co-occurring (Fig. 3c).
The final approach we took to understand the extent to which global economic trade is treated within recent IPCC reports is the feature similarity analysis (cluster dendrograms) (Fig. 4). Results of this analysis demonstrate that the clustering of trade-related keywords show similar, but not identical, results among all of the reports. The keywords "transport" and "product," again, appear the highest for most of the reports, but are not clustered with other trade related words (Fig. 4). This indicates that although the words "product" and "transport" appear more frequently in the documents than other words in general, they are not related to, and are not occurring in the context of, trade and transportation. The smallest height and distance between keywords forming clusters of crosslinked topics indicate which keywords are being discussed together. For example, in AR5 SYR, a cluster of the words "globalization," "cargo," and "commodity" appear under the same tree and within shorter distances, indicating that these words occur in closer proximity to each other in the text analyzed (Fig. 4e). However, as the SYR is a much shorter synthesis report, many words and concepts will appear closer together compared with the much longer and more detailed AR5 WGII or WGIII reports.

\section{Discussion}

Trade-related keywords, including "cargo," "commodity," "export," "freight," "globalization," "goods," "import," 


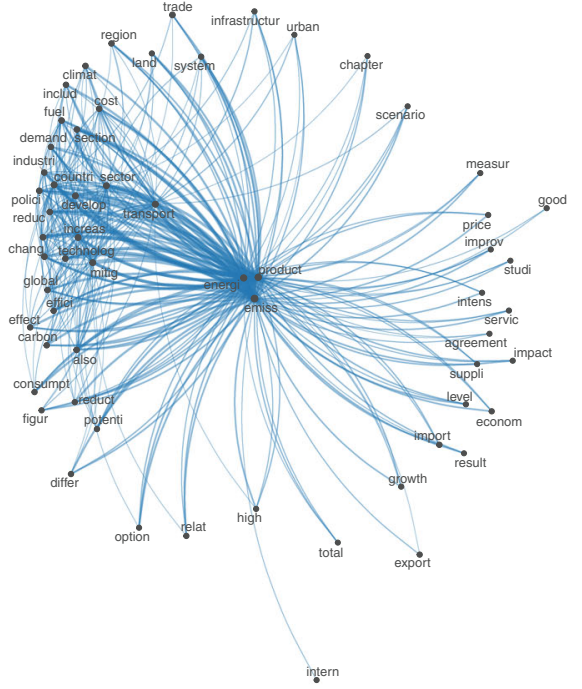

(a) AR5 WGIII

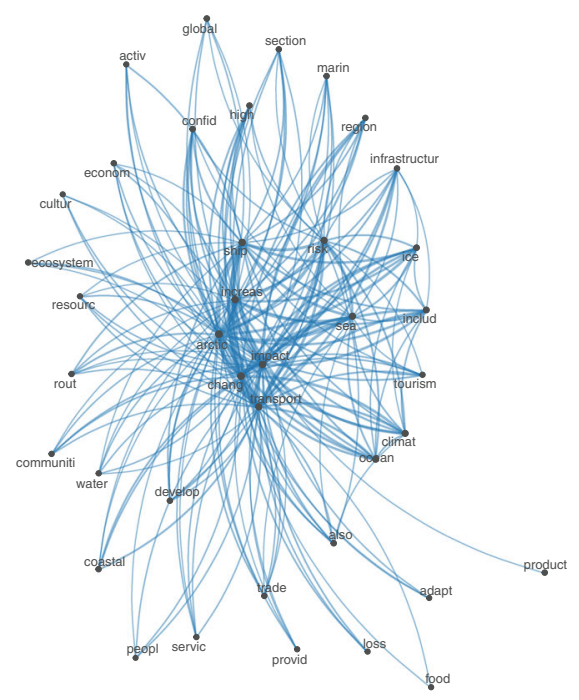

(d) SROCC

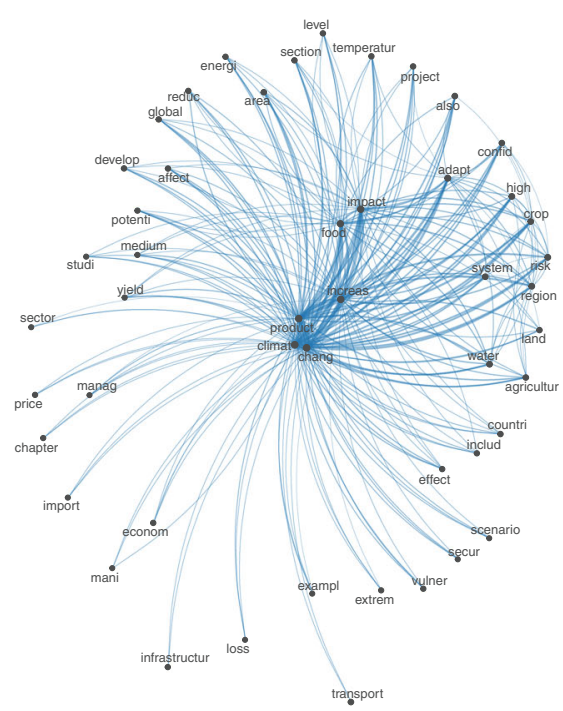

(b) AR5 WGII

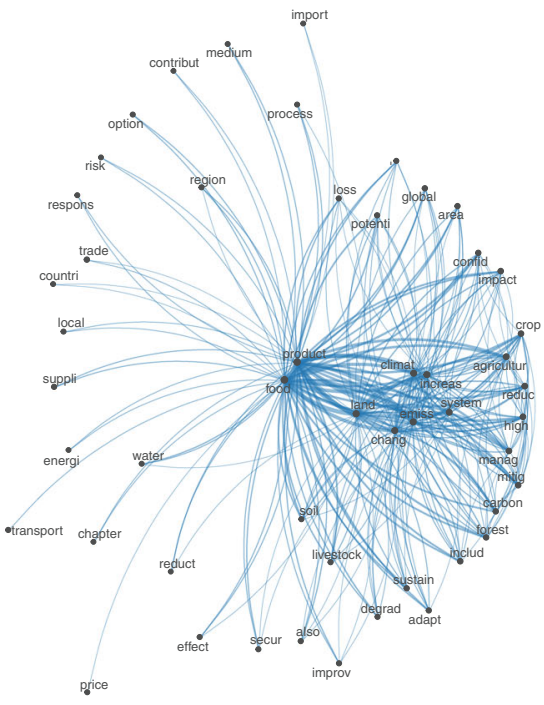

(e) SRCCL

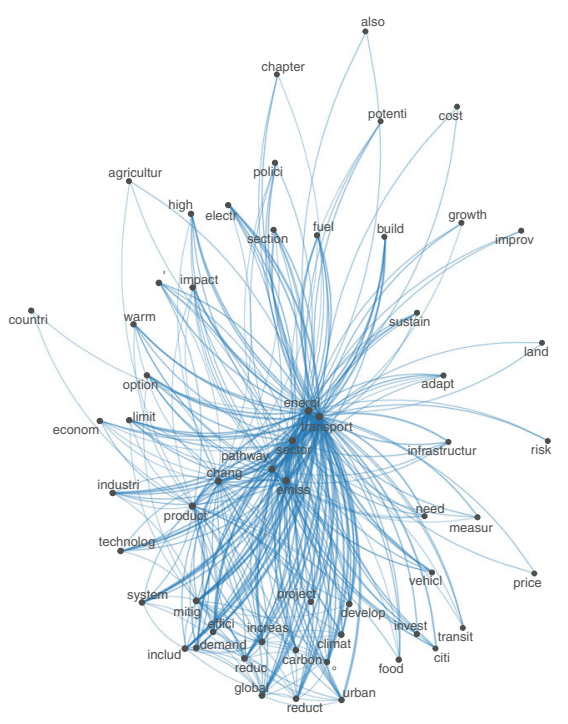

(c) SR15

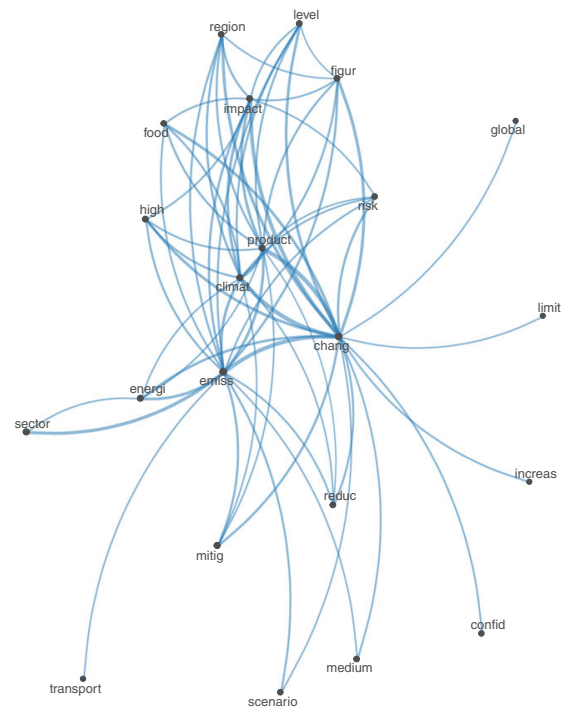

(f) SYR

Fig. 3 Frequency co-occurrence matrix graphs for word co-occurrences in each IPCC report

"product," "shipping," "trade," and "transport," appeared 4861 times in recent IPCC reports that collectively total over 5500 pages (Fig. 2). When trade-related keywords appear in the text, they are not generally used in the context of international economic trade. Rather, these words are used to cover topics such as food production, food security, energy use, emissions, and migration (Table 1, Fig. 3, Supplementary Material B and C). For example, the FCM analysis shows that there were numerous mentions of the keywords "product" and "transport" (Figs. 2 and 4, Table 1), but in the majority of these cases, they did not co-occur with other trade related keywords, suggesting that the focus of the text is not on international economic trade (Table 1, Fig. 3, Fig. 4). Other tradefocused keywords, such as "trade," "import," "freight," and "cargo," do appear to cluster together, meaning that they are related and that the text is likely referring either implicitly or explicitly to global (and or regional) economic trade (Fig. 4). However, these words co-occur infrequently (Fig. 3), suggesting that international economic trade has not been treated with any intentionality or in any comprehensive way within recent IPCC assessments.

Despite the finding that international economic trade does not seem to appear with any great frequency in recent IPCC reports, the concept of trade is by no means entirely ignored. When keywords appear related to the topic of economic trade, the text is generally focusing on either: (1) total emissions resulting from transportation (some of which is attributable to global economic trade) or (2) the idea that climate change will negatively impact the global trade system through an increase in extreme weather events, specifically focusing on 


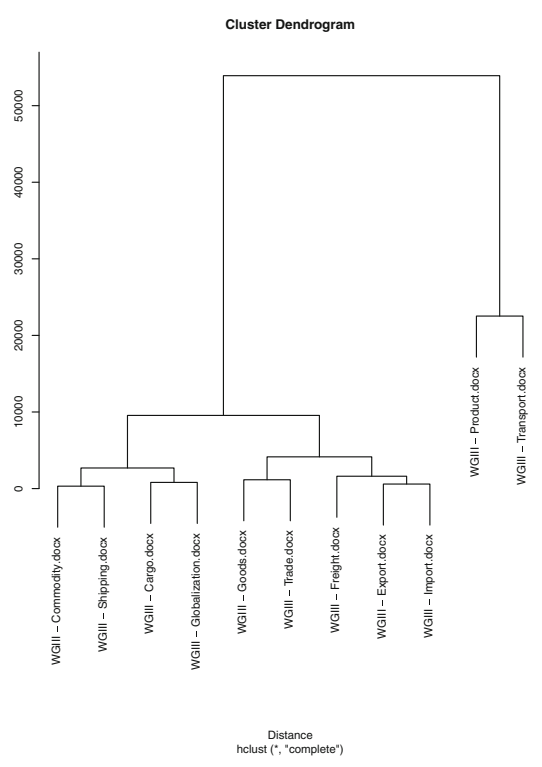

(a) AR5 WGIII

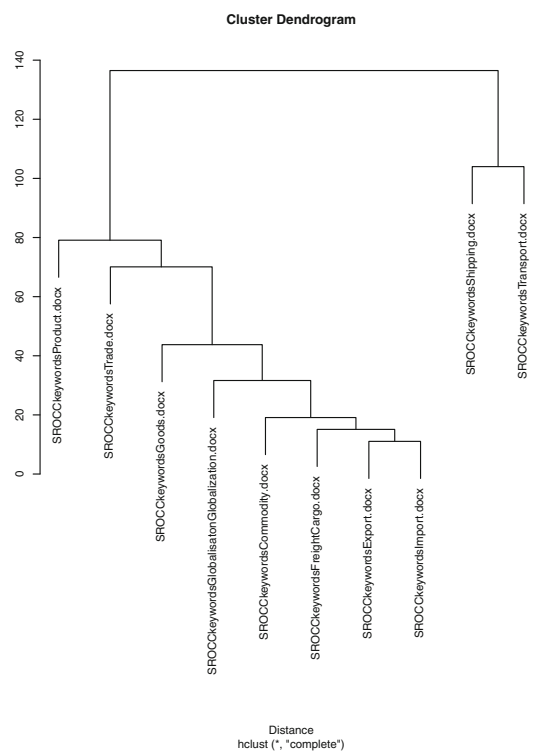

(d) SROCC

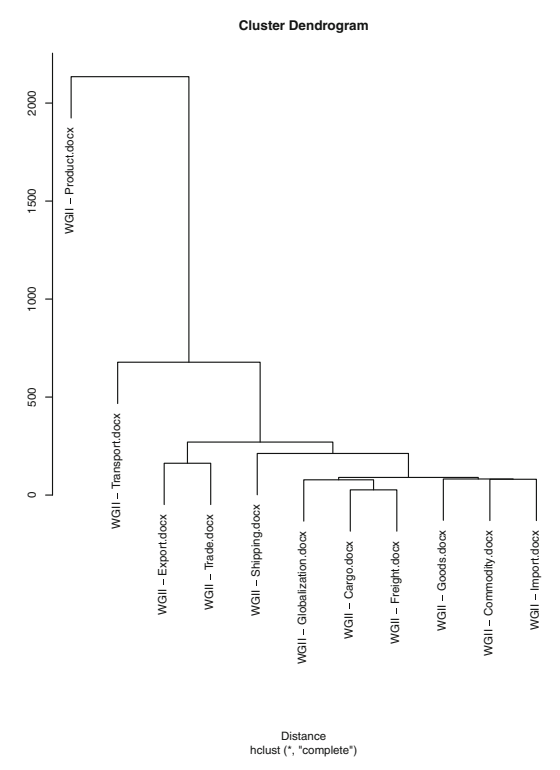

(b) AR5 WGII

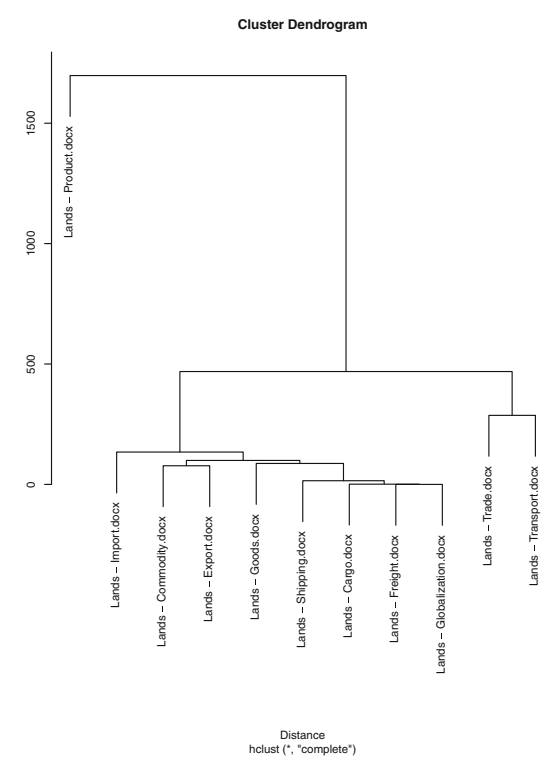

(e) SRCCL

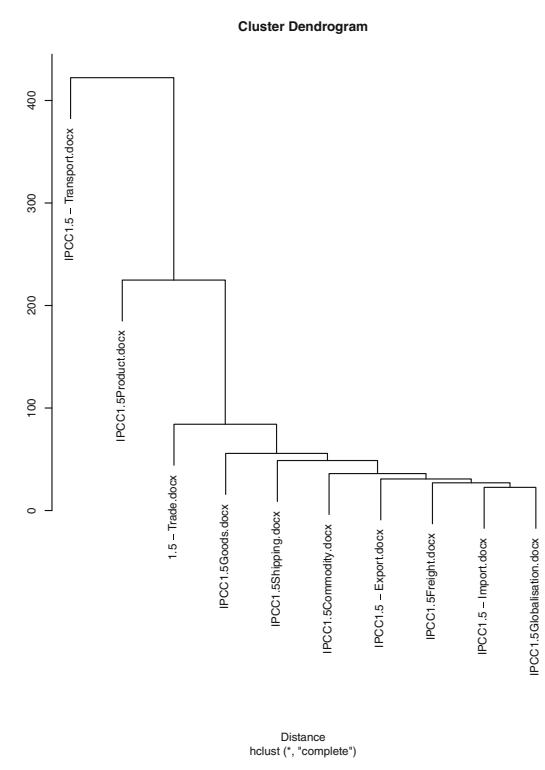

(c) SR15

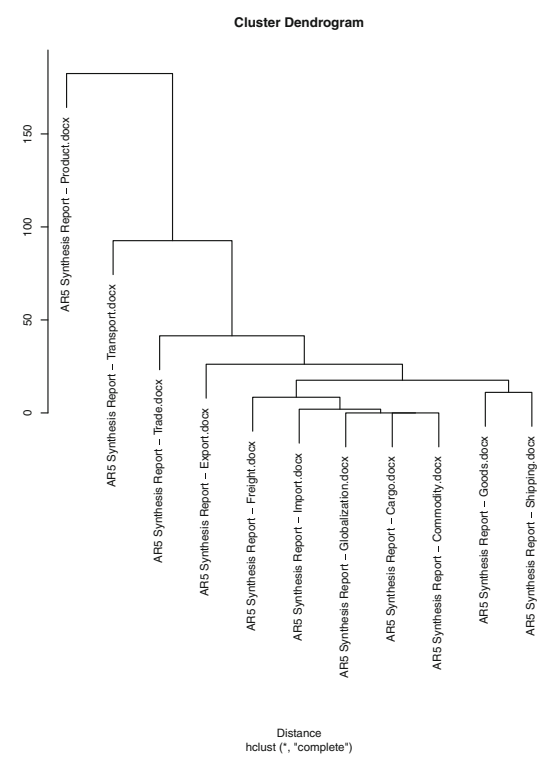

(f) SYR
Fig. 4 Cluster dendrograms including all preselected keywords for each IPCC report. The higher the height of the keyword in the cluster dendrogram, the more dissimilar (distant) it is to the other keywords in

how drought impacts global food systems. The general trend observed within these specific cases is that there tends to be a focus on negative impacts. However, in some reports, in particular the SROCC [26], specific examples are given where climate change is described as a potential benefit to the trade system - specifically, through increased accessibility to maritime Arctic trade routes from decreased sea ice extent (also see Table 1, Fig. 3d).

A major finding of this study is that trade-related keywords such as "transport" and "trade" frequently co-occur with the term "emissions" (Table 1, Fig. 2). This suggests that any treatment of trade in recent IPCC reports tends to focus on the report. The closer the height and the connecting gap between the keywords the more similarity (proximity) they have in the report

the role that the transportation sector, within the trade system, amplifies climate change. Thus, not surprisingly, the report that exhibits the highest number of trade-related keywords is AR5 WGIII (Mitigation). For example, the WGIII report specifically includes a section on the role of mitigation (i.e., reducing emissions in this case) on the global trade system (Section 13.8), which is titled "Interactions Between Climate Change Mitigation Policies and Trade" [41]. Trade accounts for up to $1 / 4$ of global greenhouse gas emissions, so reducing emissions from the trade sector would require significant changes to the system and with coincident and substantial climate-related benefits [8]. 
In the WGIII report, and also in the SRCCL report, there was a heavy emphasis on food production, with specific sections dedicated to emissions related to the movement of food (e.g., WGII Chapter 7, Chapter 9, and Chapter 21) [11, 12, 38, 42]. The word "food" occurs very frequently in WGIII and in the SRCCL and cooccurs with many other common words, indicating that "food" in general is a central theme of those documents (Fig. 3b and e, Table 1) and that treatment of the concept of trade most typically occurs under the guise of food production and transportation. One of the key reasons for this is the concern that bioenergy with carbon capture and storage and afforestation - two critical components of pathways that attain stringent $1.5{ }^{\circ} \mathrm{C}$ end of century targets-may interact with the food system through the diversion of agricultural inputs and land for climate mitigation [51].

Another important finding from the study is that traderelated keywords do not often co-occur and are rarely mentioned in the context of impacts, risk, and adaptation, which is the focus of WGII. Although there are some sections of the AR5 WGII report that focus on regional trade (Chapters 24 and 25) [39, 40] and others that focus on the impact of climate change on shipping (e.g., Section 30.6.2.3) [39, 40], overall, trade-related keywords appear very infrequently (Fig. 2). There is very little discussion of the impacts or risks of climate change on different transport modes (air, rail, road, shipping, multimodal), despite a large body of recent literature outlining the importance $[20,21,52$, e.g.]. As mentioned above, and similar to trends observed in the AR5 WGIII report, when trade is being discussed, the focus is often on food production and the movement of food products while largely ignoring other sectors (Fig. 2). However, in Canada, for example, exports from the agri-food industry made up only $7 \%$ of the total value of exported goods in 2019 , with energy and motor vehicles making up 19\% and $15 \%$, respectively [53]. It is possible that the limited treatment of trade within the WGII report occurred because of an abundance of literature on food and fiber products and the more limited number of published studies that explicitly examine climate change impacts on manufacturing, construction, energy and natural resources, and other economic sectors $[54,55]$.

Indeed, the majority of literature on economic trade, and in particular that which is focused on different economic sectors, may exist outside the expertise and scope of the literature that IPCC authors tend to review. Often, these studies on economic trade do not specifically or explicitly mention climate change, making them more difficult to find, consider, and assess. Further, economic modelingbased studies are often conducted by researchers without climate expertise, and it is indeed extremely difficult to model economic trade in tandem with climate change. Many of the existing models that are used to understand climate policies are of a partial equilibrium nature so cannot easily capture trade. CGE models can do this but are a more specialized subset of integrated assessment models (IAM) and face more challenges capturing the longer-term time horizons of climate policy and also have trade-offs on the explicit representation of technologies. Further, integrating climate damages into models that focus on climate mitigation costs remains a longer term goal of the IAM community. There is certainly a pressing need to address these modeling gaps and to consider the impact and risks that climate change has, and could have, on global economic trade within the wider academic literature. Other factors that could limit the full assessment of trade (and other commerce related subjects) could be based on author team composition, which may have led to certain topics being underrepresented within the IPCC reports where subject matter experts are not present [56, 57]. Despite these challenges, relevant literature on international economic trade, including environmental-related disruptions to supply chains and changing trade patterns and routes, does exist and should be properly assessed for inclusion within IPCC reports [58]. Because there is indeed a limited number of papers that explicitly examine climate change and international economic trade, it will be more challenging, but still possible, to review and assess relevant peer reviewed literature that indeed covers aspects of trade and climate change (separately or in some case implicitly) for inclusion in future IPCC reports.

\section{Conclusion}

Society as we know it is based upon the international trade of goods and services, and climate change is expected to affect all aspects of the global economic trade system. Despite the importance of trade and the transport of goods on the global economy and society, little attention has been paid to this topic in recent IPCC assessments and special reports. Using preselected keywords related to trade, we were able to evaluate the overall treatment of trade within six recent (2012-2019) IPCC reports, determining that, overall, trade is not intentionally nor comprehensively covered in any of the recent reports. The WGIII (mitigation) report does the best job, discussing trade through a focus on emissions resulting from transportation, while WGII (impacts and adaptation) has neglected to consider the impacts, risks, or adaptation options that will be needed to ensure a safe, secure, and efficient global economic trade system. The lack of attention paid to trade within the IPCC reports is surprising considering the global importance of trade for sustainable economic development and the focus that the United Nations Framework Convention on Climate Change (UNFCCC) places 
on climate action within an equitable and climate-resilient development framework [59]. Given the recent shift in the goals of the IPCC toward solutions-oriented reporting $[60,61]$, the urgency in intentionally and comprehensively assessing the role of climate change on global economic trade, including adaptation options focused on securing important supply chains, has only increased.

Based on the results of this study and others $[19,20,52,54$, 55], it is recommended that specific attention be paid to the impacts of climate change on trade and transport. This should signal a call to the academic community to concentrate research efforts on this topic to ensure that ample literature is in circulation for future assessment by the IPCC. It could be achieved through a variety of efforts within the IPCC ecosystem, for example, by devoting a cross-chapter box to climate change and economic trade, organizing a workshop or special meeting, or at some point in the future, by dedicating a special report to the global trade system or to climate change and the economy more generally. There is a large body of literature that outlines the impacts of climate change on transport infrastructure, and this needs to be discussed and treated more intentionally and more comprehensively in future IPCC assessment and special reports. To achieve this in the near term (i.e., for AR6), IPCC authors will be required to review relevant literature that exists outside of the climate change context, and which addresses the importance of trade generally, as well as for key trade routes, potentially vulnerable infrastructure, and key gaps in existing trade models. This will need to involve collaborations between social and physical scientists, as well as economic and IAM modelers. There is an important opportunity within the upcoming IPCC AR6 assessment report to explicitly link the importance of global economic trade by outlining the co-benefits of mitigation and adaptation around this theme through synergies between WGII and WGIII and within the synthesis report. Increased explicit treatment of global economic trade by the IPCC overall is imperative to fully understand the impacts, risks, adaptation options, and mitigation needs related to climate change on the trade system, which are very likely to affect the global economy and all of society.

Acknowledgments The authors would like to acknowledge the support provided for this research from the Canada Research Chairs program, Clear Seas, ArcticNet, and MEOPAR.

Open Access This article is licensed under a Creative Commons Attribution 4.0 International License, which permits use, sharing, adaptation, distribution and reproduction in any medium or format, as long as you give appropriate credit to the original author(s) and the source, provide a link to the Creative Commons licence, and indicate if changes were made. The images or other third party material in this article are included in the article's Creative Commons licence, unless indicated otherwise in a credit line to the material. If material is not included in the article's Creative Commons licence and your intended use is not permitted by statutory regulation or exceeds the permitted use, you will need to obtain permission directly from the copyright holder. To view a copy of this licence, visit http://creativecommons.org/licenses/by/4.0/.

\section{References}

1. World Bank. World Bank Open Data. 2020. Accessed March, 2020. https://data.worldbank.org/.

2. World Bank. Trade Overview. 2020. Accessed March, 2020. https:/www.worldbank.org/en/topic/trade/overview/.

3. Eaton J, Kortum S, Neiman B, Romalis J. Trade and the global recession. Am Econ Rev. 2016;106(11):3401-38.

4. National Bureau of Economic Research. Is trade good or bad for the environment? n.d. Accessed March, 2020. https://www.nber.org/ digest/nov02/w9021.html.

5. Shapiro JS. Trade costs, $\mathrm{CO}_{2}$, and the environment. Am Econ J Econ Pol. 2016;8(4):220-54

6. Asariotis R, Benamara H. Maritime transport and the climate change challenge. New York: Earthscan/Routledge; 2012.

7. Pendakur K. Northern territories. In: Palko K, Lemmen DS, editors. Climate risks and adaptation practices for the Canadian transportation sector 2016. Ottawa: Government of Canada; 2017. p. 27-64.

8. Peters GP, Minx JC, Weber CL, Edenhofer O. Growth in emission transfers via international trade from 1990 to 2008. Proc Natl Acad Sci USA. 2011;108(21):8903-8.

9. Peters GP, Hertwich E. $\mathrm{CO}_{2}$ embodied in international trade with implications for global climate policy. Environ Sci Technol. 2008;42(5):1401-7.

10. Victor DG. The Case for Climate Clubs. E15Initiative. Geneva: International Centre for Trade and Sustainable Development (ICTSD) and World Economic Forum. 2015. Accessed March, 2020. http://e15initiative.org/publications/the-case-for-climateclubs/.

11. Cai Y, Riezman R, Whalley J. International trade and the negotiability of global climate change agreements. Econ Model. 2013;33: 421-7.

12. Newell RG, Pizer WA, Raimi D. Carbon markets: past, present, and future. Annu Rev Resour Econ. 2014;6(1):191-215.

13. Füssel H-M. Modeling impacts and adaptation in global IAMs. WIREs Clim Chang. 2010;1(2):288-303.

14. Nelson GC, Valin H, Sands RD, Havlík P, Ahammad H, Deryng D, et al. Climate change effects on agriculture: economic responses to biophysical shocks. P rocNatl Acad Sci USA. 2014;111(9):3274-9.

15. Abbott P, de Battisti AB. Recent global food price shocks: causes, consequences and lessons for African governments and donors. J Afr Econ. 2011;20(Suppl. 1):112-62.

16. Adam C, Ajakaiye O. Causes, consequences and policy implications of global food price shocks: introduction and overview. J Afr Econ. 2011;20(Suppl_1):i3-i11.

17. Bosello F, Nicholls RJ, Richards J, Roson R, Tol RSJ. Economic impacts of climate change in Europe: sea-level rise. Clim Chang. 2011;112(1):63-81.

18. Grenzeback LR, Lukmann AT. Case study of the transportation sector's response to and recovery from hurricanes Katrina and Rita. Cambridge: Cabmridge Systematics, Inc.; 2007.

19. Melvin AM, Larsen P, Boehlert B, et al. Climate change damages to Alaska public infrastructure and the economics of proactive adaptation. Proc Natl Acad Sci. 2016;114(2):E122-31.

20. Chinowsky P, Helman J, Gulati S, Neumann J, Martinich J. Impacts of climate change on operation of the US rail network. Transp Policy. 2019;75:183-91.

21. Smythe T. Assessing the impacts of hurricane sandy on the port of New York and New Jersey's maritime responders and response infrastructure. Quick Response Report No. 238: Final Report to the University of Colorado Natural Hazards Center. 2013. Accessed March, 2020. https://hazards.colorado.edu/uploads/ quick_report/smythe_2013.pdf. 
22. Ng AKY, Andrews J, Babb D, Lin Y, Becker A. Impacts of climate change for shipping: opening the Arctic seas. WIREs Clim Chang. 2018;9(2):e507.

23. Barnhart KR, Miller CR, Overeem I, Kay JE. Mapping the future expansion of Arctic open water. Nat Clim Chang. 2016;6:280-5.

24. Pizzolato L, Howell SEL, Dawson J, Laliberté F, Copland L. The influence of declining sea ice on shipping activity in the Canadian Arctic. Geophys Res Lett. 2016;43(23):146-54.

25. Haas C, Howell SEL. Ice thickness in the Northwest Passage. Geophys Res Lett. 2015;42(18):7673-80.

26. IPCC. Special report on the ocean and cryosphere in a changing climate [H.- O. Pörtner, D.C. Roberts, V. Masson-Delmotte, P. Zhai, M. Tignor, E. Poloczanska, K. Mintenbeck, M. Nicolai, A. Okem, J. Petzold, B. Rama, N. Weyer (eds.)]. 2019a;755.

27. Dawson J, Pizzolato L, Howell SEL, Copland L, Johnston ME. Temporal and spatial patterns of ship traffic in the Canadian Arctic from 1990 to 2015. Arctic. 2018;71(1):15-26.

28. Eguíluz VM, Fernández-Gracia J, Irigoien X, Duarte CM. A quantitative assessment of Arctic shipping in 2010-2014. Sci Rep. 2016;6:30682.

29. Becker AH, Acciaro M, Asariotis R, Cabrera E, Cretegny L, Crist $\mathrm{P}$, et al. A note on climate change adaptation for seaports: a challenge for global ports, a challenge for global society. Clim Chang. 2013;120:683-95.

30. Dawson J, Carter N, van Luijk N, Parker C, Weber M, Cook A, et al. Infusing Inuit and local knowledge into the low impact shipping corridors: an adaptation to increased shipping activity and climate change in Arctic Canada. Environ Sci Pol. 2020;105:19-36.

31. Yumashev D, van Hussen K, Gille J, Whiteman G. Towards a balanced view of Arctic shipping: estimating economic impacts of emissions from increased traffic on the Northern Sea route. Clim Chang. 2017;143:143-55.

32. Huntington HP, Begossi A, Gearheard SF, et al. How small communities respond to environmental change: patterns from tropical to polar ecosystems. Ecol Soc. 2017;22(3):9.

33. Ebi KL. Key themes in the working group II contribution to the intergovernmental panel on climate change 5 th assessment report. Clim Chang. 2012;114(3-4):417-26.

34. Woodward A, Smith KR, Campbell-Lendrum D, Chadee DD, Honda Y, Liu Q, et al. Climate change and health: on the latest IPCC report. Lancet. 2014;383(9924):1185-9.

35. Beck S, Mahony M. The IPCC and the politics of anticipation. Nat Clim Chang. 2017;7:311-3.

36. Ford JD, King D. Coverage and framing of climate change adaptation in the media: a review of influential North American newspapers during 1993-2013. Environ Sci Pol. 2015;48:137-46.

37. Hulme M, Mahony M. Climate change: what do we know about the IPCC? Prog Phys Geogr. 2010;34(5):705-18.

38. IPCC. Climate Change 2014: Synthesis Report. Contribution of Working Groups I, II and III to the Fifth Assessment Report of the Intergovernmental Panel on Climate Change [Core Writing Team, R.K. Pachauri and L.A. Meyer (eds.)]. IPCC, Geneva, Switzerland, 2014a; 151

39. IPCC. Climate Change 2014: Impacts, Adaptation, and Vulnerability. Part A: Global and Sectoral Aspects. Contribution of Working Group II to the Fifth Assessment Report of the Intergovernmental Panel on Climate Change [Field, C.B., V.R. Barros, D.J. Dokken, K.J. Mach, M.D. Mastrandrea, T.E. Bilir, M. Chatterjee, K.L. Ebi, Y.O. Estrada, R.C. Genova, B. Girma, E.S. Kissel, A.N. Levy, S. MacCracken, P.R. Mastrandrea, and L.L. White (eds.)]. Cambridge University Press, Cambridge; 2014b:1132.

40. IPCC. Climate Change 2014: Impacts, Adaptation, and Vulnerability. Part B: Regional Aspects. Contribution of Working Group II to the Fifth Assessment Report of the Intergovernmental Panel on Climate Change [Barros, V.R., C.B.
Field, D.J. Dokken, M.D. Mastrandrea, K.J. Mach, T.E. Bilir, M. Chatterjee, K.L. Ebi, Y.O. Estrada, R.C. Genova, B. Girma, E.S. Kissel, A.N. Levy, S. MacCracken, P.R. Mastrandrea, and L.L. White (eds.)]. Cambridge University Press, Cambridge; 2014c: 688.

41. IPCC. Climate Change 2014: Mitigation of Climate Change. Contribution of Working Group III to the Fifth Assessment Report of the Intergovernmental Panel on Climate Change [Edenhofer, O., R. Pichs-Madruga, Y. Sokona, E. Farahani, S. Kadner, K. Seyboth, A. Adler, I. Baum, S. Brunner, P. Eickemeier, B. Kriemann, J. Savolainen, S. Schlömer, C. von Stechow, T. Zwickel and J.C. Minx (eds.)]. Cambridge University Press, Cambridge; 2014d:1435.

42. IPCC. Climate Change and Land: an IPCC special report on climate change, desertification, land degradation, sustainable land management, food security, and greenhouse gas fluxes in terrestrial ecosystems [P.R. Shukla, J. Skea, E. Calvo Buendia, V. MassonDelmotte, H.-O. Pörtner, D. C. Roberts, P. Zhai, R. Slade, S. Connors, R. van Diemen, M. Ferrat, E. Haughey, S. Luz, S. Neogi, M. Pathak, J. Petzold, J. Portugal Pereira, P. Vyas, E. Huntley, K. Kissick, M. Belkacemi, J. Malley, (eds.)]. 2019b;864.

43. IPCC. Global Warming of $1.5^{\circ} \mathrm{C}$ : An IPCC Special Report on the impacts of global warming of $1.5^{\circ} \mathrm{C}$ above pre-industrial levels and related global greenhouse gas emission pathways, in the context of strengthening the global response to the threat of climate change, sustainable development, and efforts to eradicate poverty [MassonDelmotte, V., P. Zhai, H.-O. Pörtner, D. Roberts, J. Skea, P.R. Shukla, A. Pirani, W. Moufouma-Okia, C. Péan, R. Pidcock, S. Connors, J.B.R. Matthews, Y. Chen, X. Zhou, M.I. Gomis, E. Lonnoy, T. Maycock, M. Tignor, and T. Waterfield (eds.)]. 2018;616.

44. IPCC. Managing the Risks of Extreme Events and Disasters to Advance Climate Change Adaptation: A Special Report of Working Groups I and II of the Intergovernmental Panel on Climate Change [Field, C.B., V. Barros, T.F. Stocker, D. Qin, D.J. Dokken, K.L. Ebi, M.D. Mastrandrea, K.J. Mach, G.-K. Plattner, S.K. Allen, M. Tignor, and P.M. Midgley (eds.)]. Cambridge University Press, Cambridge; 2012: 582.

45. Benoit $\mathrm{K}$, Watanabe $\mathrm{K}$, Wang $\mathrm{H}$, et al. quanteda: An $\mathrm{R}$ package for the quantitative analysis of textual data. J Open Source Softw. 2018;3(30):774.

46. Bucchi M, Loner E, Fattorini E. Give science and peace a chance: speeches by Nobel laureates in the sciences, 1901-2018. PLoS One. 2019;14(10):e0223505.

47. Momtazi S, Khudanpur S, Klakow D. A comparative study of word co-occurrence for term clustering in language model-based sentence retrieval. Human Language Technologies: The 2010 Annual Conference of the North American Chapter of the ACL, Los Angeles, California. 2010;325-328.

48. Jurafsky D, Martin JH. Vector Semantics and Embeddings. In: Jurafsky D, Martin JH, ed. From speech and language processing: an introduction to natural language processing, computational linguistics, and speech recognition. 2019. Accessed March, 2020. https://web.stanford.edu/ jurafsky/slp3/.

49. Church KW, Hanks P. Word association norms, mutual information, and lexicography. In: $27^{\text {th }}$ Annual Meeting of the Association for Computational Linguistics, Vancouver, Canada. 1989:76-83.

50. Wise JA, Thomas JJ, Pennock K, et al. Visualizing the non-visual: spatial analysis and interaction with information from text documents. In: Proceedings of Visualization 1995 Conference, Atlanta, GA, USA. 1995:51-58.

51. Muratori M, Calvin K, Wise M, Kyle P, Edmonds J. Global economic consequences of deploying bioenergy with carbon capture and storage (BECCS). Environ Res Lett. 2016;11(9):095004. 
52. Matualla C, Hollosi B, Andre K, et al. Climate change driven evolution of hazards to Europe's transport infrastructure throughout the twenty-first century. Theor Appl Climatol. 2018;133:227-42.

53. Global Affairs Canada. Canada's State of Trade 2019. 2019. Accessed March, 2020. https://www.international.gc.ca/gac-amc/ publications/economist-economiste/state_of_trade-commerce international-2019.aspx?lang=eng\#Section1.1.

54. Lazo JK, Lawson M, Larsen PH, Waldman DM. U.S. economic sensitivity to weather variability. Bull Am Meteorol Soc. 2011;92(6):709-20.

55. Dolfman ML, Wasser S, Bergman B. The effects of hurricane Katrina on the New Orleans economy. Mon Labor Rev. 2007;130(6):3-18.

56. Ford J, Cameron L, Rubis J, et al. Including indigenous knowledge and experience in IPCC assessment reports. Nat Clim Chang. 2016;6:349-53.
57. Porter J, Howden M, Smith P. Considering agriculture in IPCC assessments. Nat Clim Chang. 2017;7:680-3.

58. Peters GP, Andrew R, Lennox J. Constructing an environmentallyextended multi-regional input-output table using the GTAP database. Econ Syst Res. 2011;23(2):131-52.

59. United Nations. What is the United Nations Framework Convention on Climate Change? n.d. Accessed March, 2020. https://unfccc.int/process-and-meetings/the-convention/what-isthe-united-nations-framework-convention-on-climate-change.

60. Kowarsch M, Jabbour J. Solution-oriented global environmental assessments: opportunities and challenges. Environ Sci Pol. 2017;77:187-92.

61. Tollefson J. Is the $2{ }^{\circ} \mathrm{C}$ word a fantasy? Nat News. 2015;527:436-8.

Publisher's Note Springer Nature remains neutral with regard to jurisdictional claims in published maps and institutional affiliations. 